\title{
Neovascularization in Purtscher's retinopathy
}

This article was published in the following Dove Press journal:

Clinical Ophthalmology

2 November 2011

Number of times this article has been viewed

\section{Annie Chan \\ Douglas R Fredrick \\ Theodore Leng}

Department of Ophthalmology, Byers Eye Institute at Stanford University,

Stanford University School of

Medicine, Stanford, CA, USA
Correspondence: Theodore Leng Byers Eye Institute at Stanford University, Horngren Vitreoretinal Center, 2452 Watson Court, MC 5353,

Palo Alto, CA 94303, USA

$\mathrm{Tel}+\mathrm{I} 6504984264$

Fax + I 6505658297

Email tedleng@stanford.edu
Abstract: We report a case of neovascularization secondary to Purtscher's retinopathy that showed minimal improvement with photocoagulation treatment. A 14-year-old boy with a history of cerebellar medulloblastoma presented with blurry vision and floaters after being struck by a motor vehicle while riding his bike. At presentation, visual acuity was 20/400 in his right eye and counting fingers in his left eye. Fundus examination showed disk edema, retinal whitening, and retinal hemorrhages in both eyes. Optical coherence tomography demonstrated thinning of the temporal retina and disruption of the inner segment-outer segment junction of the photoreceptor layer in the right eye and thickening and edema of the nasal macula, as well as a central foveal hyper-reflectivity, in the left eye. At the initial visit, there was no ischemia or neovascularization (NV). One month later, the patient developed NV of the disk and ischemia in the mid-periphery of the left eye. The patient underwent treatment with pan-retinal photocoagulation. The NV regressed, but visual outcome remained poor at his 5-month follow-up visit.

Keywords: Purtscher's retinopathy, neovascularization, laser photocoagulation, disk edema

\section{Introduction}

Purtscher's retinopathy was first described in 1910 by Otmar Purtscher in five patients who suffered acute blindness after sustaining severe trauma. ${ }^{1}$ The patients exhibited multiple areas of retinal whitening in the posterior pole which are now recognized as cotton wool spots. Papillitis, intraretinal hemorrhage, and preretinal hemorrhage were also seen. The severity of visual loss in Purtscher's retinopathy is typically bilateral and variable. The onset of visual symptoms may be acute or delayed by up to 48 hours. Without treatment, vision usually recovers spontaneously within 1-3 months. The fundus examination may be characterized by mottling of the retinal pigment epithelium, temporal disk pallor, and attenuation or sheathing of the retinal vessels. ${ }^{2}$ Rarely, neovascularization can occur. ${ }^{3,4}$

\section{Case report}

A 14-year-old boy was referred to the ophthalmology service for new blurry vision and floaters in both eyes. A few days earlier, he had suffered multiple fractures to his face and skull after being struck by a truck while riding his bike. He also had a lacerated liver and pancreas, a small pneumothorax, and a pelvic hematoma. He did not require any surgical intervention. His medical history was significant for cerebellar medulloblastoma that had been treated with surgery, radiation, and chemotherapy 6 years prior to presentation. 
Visual acuity was 20/400 in the right eye and counting fingers at 5 feet in the left eye. An afferent pupillary defect was not present. Intraocular pressure was $21 \mathrm{mmHg}$ in the right eye and $19 \mathrm{mmHg}$ in the left eye. Slit lamp examination revealed trace cell in the anterior vitreous in the right eye. Dilated fundus examination revealed disk edema, retinal whitening, and retinal hemorrhages in both eyes (Figure 1A and B). Optical coherence tomography showed atrophy of the temporal retina and disruption of the inner segment-outer segment junction of the photoreceptor layer in the right eye (Figure 1C and E) with thickening and edema of the nasal macula, and central foveal hyper-reflectivity consistent with a scar in the left eye (Figure 1D). One month later, the right eye was without neovascularization (Figure 2) and the patient was found to have neovascularization of the disk and ischemia in the mid-periphery in the left eye (Figure 3). He underwent uncomplicated pan-retinal photocoagulation. At the last follow-up, 5 months after his initial presentation, visual acuity had slightly improved to $20 / 200$ in the right eye and 20/300 in the left eye. The neovascularization had regressed (Figure 4), and he was referred to low vision services.
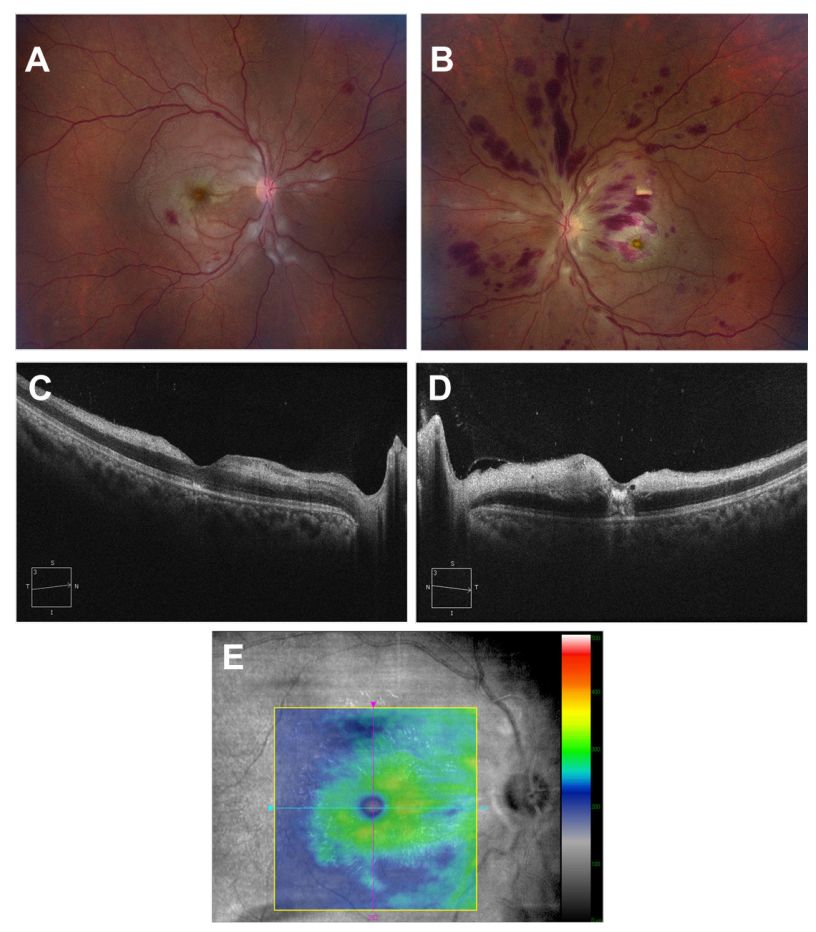

Figure I (A and B) Color fundus photograph montages showing disk edema, diffuse retinal whitening, and retinal hemorrhages more prominent in the left eye compared to the right eye. (C) Optical coherence tomography showing atrophy of the temporal retina and disruption of inner segment-outer segment junction of the photoreceptor in the right eye. (D) Optical coherence tomography revealing edema of the nasal macula and central foveal hyper-reflectivity consistent with a scar in the left eye. (E) Optical coherence tomography thickness map of the right eye demonstrating temporal thinning.
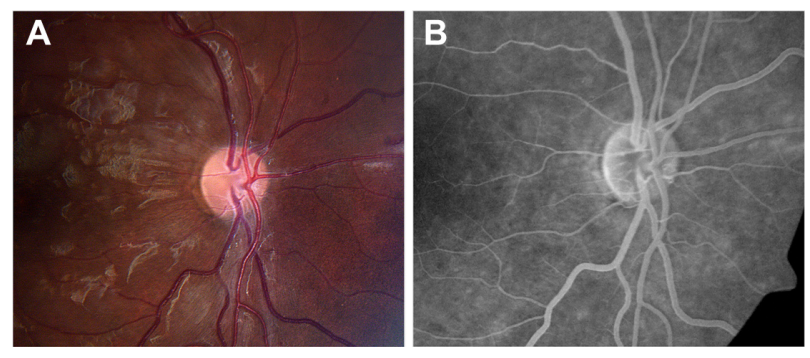

Figure 2 (A) Color photograph and (B) fluorescein angiogram of the right eye I month after presentation.

\section{Discussion}

Conditions that can have funduscopic findings similar to Purtscher's retinopathy include: compressive chest trauma, hydrostatic pressure syndrome, post-traumatic fat embolism from long bone fractures, acute pancreatitis, lupus erythematosis, dermatomyositis, scleroderma, and amniotic fluid embolism. ${ }^{5-7}$
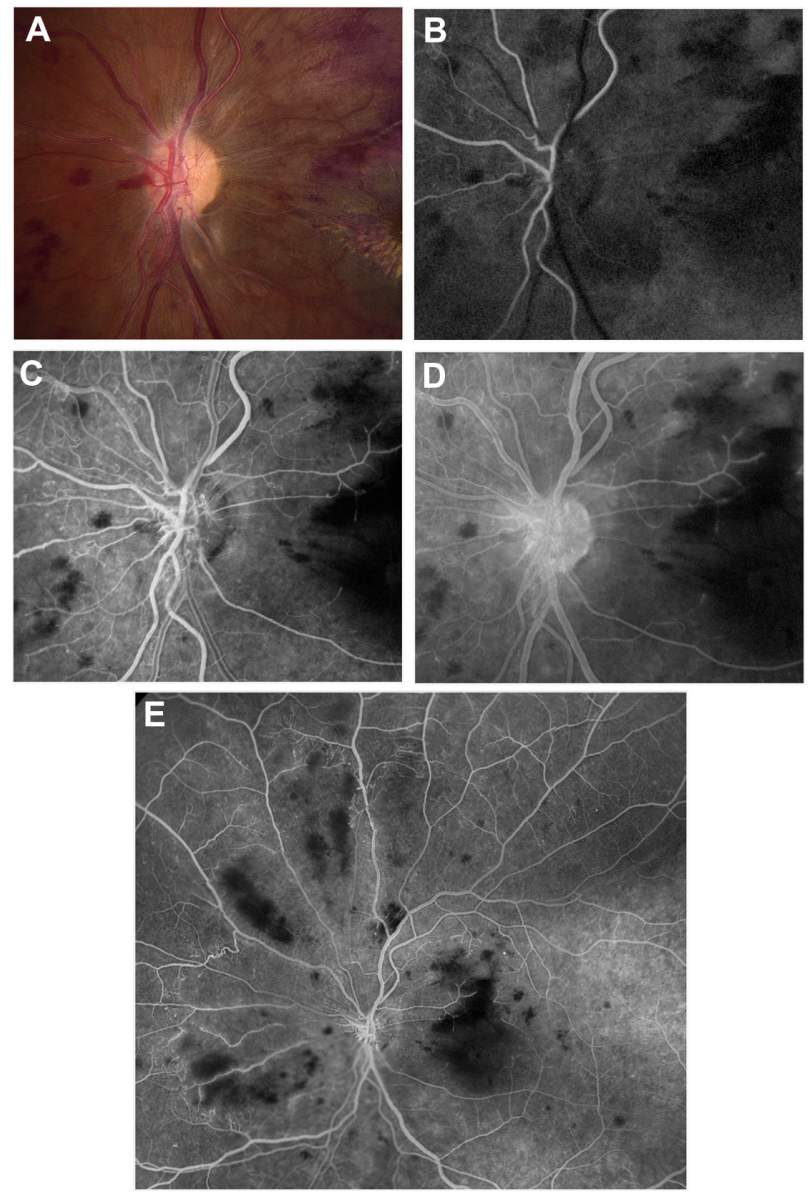

Figure 3 (A) Color photograph of the left eye I month after presentation revealing neovascularization of the disk. (B, C and D) Early, mid, and late fluorescein angiograms of the left eye at the same visit demonstrating leakage of the disk consistent with neovascularization. (E) Fluorescein angiogram of the mid-periphery revealing ischemia superonasal to the disk. 

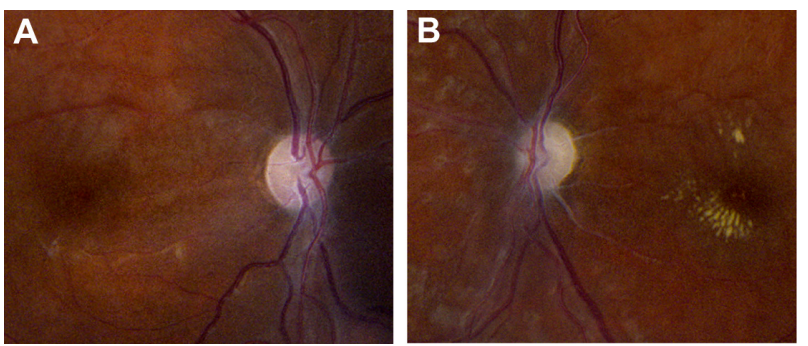

Figure 4 Color photographs of the right (A) and left (B) eyes 5 months after pan-retinal photocoagulation, demonstrating regression of neovascularization of the disk. Optic atrophy and pallor are present.

To our knowledge, this is the first reported case of neovascularization secondary to traumatic Purtscher's retinopathy treated with panretinal photocoagulation. This case illustrates that retinal ischemia can be severe enough in Purtscher's retinopathy for neovascularization to occur. Sturm et al described similar findings in two children with hemolytic uremic syndrome, one of whom required laser photocoagulation for bilateral rubeosis irides and neovascularization of the disk. ${ }^{4}$ Vision was poor as a result of optic atrophy. It is unclear why our patient did not develop neovascularization in both eyes.

The presence of ischemia certainly contributed to poor visual outcome in the left eye of our patient. Optic disk swelling, which was present in both eyes at the time of presentation, has been suggested as a prognostic factor associated with poor outcome and may also help explain the poor visual outcome. $^{2}$

In conclusion, Purtscher's retinopathy in the setting of trauma can rarely lead to neovascularization and ischemia. Even with treatment, visual prognosis can be guarded.

\section{Disclosure}

The authors report no conflicts of interest in this work.

\section{References}

1. Purtscher O. [Unknown findings after head trauma.]. Berl Dtsch Ophthal Ges. 1910;36:294-301. German.

2. Agrawal A. McKibbin Purtscher's and Purtscher-like retinopathies: a review. Surv Ophthalmol. 2006;51(2):129-136.

3. Prammer G. Disturbances of the retinal vessels as a result of Purtscher's retinopathy (author's transl). Klin Monbl Augenheilkd. 1976;168(6): 840-843. German.

4. Sturm V, Menke MN, Landau K, Laube GF, Neuhaus TJ. Ocular involvement in paediatric haemolytic uraemic syndrome. Acta Ophthalmol. 2010;88(7):804-807.

5. Kelly JS. Purtcher's retinopathy related to chest compression by safety belts: fluorescein angiographic findings. Am J Ophthalmol. 1972;74(2):2 78-283.

6. Blodi B, Johnson MW, Gass JD, Fine SL, Joffe LM. Purtcher's-like retinopathy after childbirth. Ophthalmology. 1990;97(12):1654-1659.

7. Burton TC. Unilateral Purtcher's retinopathy. Ophthalmology. 1980;87(11): 1096-1105.
Clinical Ophthalmology

\section{Publish your work in this journal}

Clinical Ophthalmology is an international, peer-reviewed journal covering all subspecialties within ophthalmology. Key topics include: Optometry; Visual science; Pharmacology and drug therapy in eye diseases; Basic Sciences; Primary and Secondary eye care; Patien Safety and Quality of Care Improvements. This journal is indexed on

\section{Dovepress}

PubMed Central and CAS, and is the official journal of The Society of Clinical Ophthalmology (SCO). The manuscript management system is completely online and includes a very quick and fair peer-review system, which is all easy to use. Visit http://www.dovepress.com/ testimonials.php to read real quotes from published authors. 